\title{
CARTA ARQUEOLÓGICA PARA UMA HUMANIDADE POSSÍVEL
}

Bruno S. Ranzani da Silva1

Eis uma carta, com notas de diário de bordo de um arqueólogo homem, cis, branco, burguês, nerd e gay.

Nós não gostamos de guerra. Nós não queremos guerra. A guerra mata pessoas, sempre, em todos os lugares e em todos os fronts. Talvez essa é uma das lições mais unânimes que tivemos em nossa trajetória com a história. Para evitar a guerra, precisamos nos unir. Precisamos estar em paz conosco e com os outros. Sim, os outros. Aqueles estranhos e estranhas que não comem o que comemos, que não rezam para quem rezamos, que não cheiram do mesmo jeito, que não são do mesmo jeito. Se os odiamos por tudo isso, vamos querer seu desaparecimento, pois só assim nosso mundo volta ao centro de tudo. E é nesse momento que Ihe perguntamos: estás disposto a perder tudo? Estás disposto a botar tua existência na roleta russa? Estás disposto a se perder a qualquer momento, como que por "bala perdida"? Talvez estejas. Talvez tua vida não tenha sentido com os outros, com esses hereges, subversivos, corrompidos. Mas nós não estamos. Nós não queremos a morte, de ninguém. Não queremos a morte da moça crente, de saia até o joelho e cabelo até o quadril. Nem da preta macumbeira, de turbante, que deixa vela e sapato de salto no cruzamento. Nem do preto que cruza as velas, dorme no frontão das casas, envolto em papelão. Nem do soldado em exercício na fronteira, no trânsito, na favela. Nem do moleque favelado a caminho da escola, na semana, e do bailinho, no fim de semana. Nem da funkeira, lacradora que vai descendo até o chão. Nem dazamiga bixa loka que requebra e faz a dyva na balada. Nem da sapa, botinuda que não depila. Nem da mocinha delicada, que segue dez canais de make no youtube. Nem da índia coqueta, que fala guarani, roça mandioca e tem seguidores no instagram. Nem do seu pajé, de boné na cabeça, casa de alvenaria e cuida do santuário de madeira e palha. Nem da soja, nem da mandioca, nem do trigo, nem do açaí. De n-i-n-g-u-é-m. 
Por isso que viemos fazer esse manifesto. Para conversar contigo sobre os perigos de uma via única, de uma única verdade, de uma única história, de um único povo ${ }^{2}$. A diferença nos assusta. Assusta as gay e assusta os crente. Mas destruir a diferença só para não termos que lidar com ela é, por fim, a destruição de nós mesmos. Porque nós somos gente, assim como vocês.

\section{CARTA PELA VIDA}

Em um polêmico e impactante artigo, o canal de pornografia Redtube (REDTUBE 2016) publicou suas estatísticas de acesso internacional, mas voltado à divulgação das preferências brasileiras (véspera de Carnaval, inclusive). O site apontou que, se fores brasileiro, tens $89 \%$ a mais de chances de escolher pornô transexual que qualquer outro país do mundo com acesso à rede. Para o mesmo período, a Transgender Europe publicou que o Brasil é o país que mais mata transexuais no mundo (TGEU 2017; SOUTO 018).

É disso que estamos falando. Dessa relação destrutiva entre si e o outro. Entre as próprias vontades e a banalização das vontades do outro. Da escravização do corpo do outro. Por que fantasiar com uma mulher/homem trans e matá-la? Por que não a aceitar e ser feliz com elx? Por que não se aceitar e ser feliz consigo e com as outra e outros? Por que não? Será que eu sou enrustido? Então eu não sou homem? Por que não sou homem? Perguntas, perguntas, perguntas. Sim, a gente sabe. Dá trabalho. Viver em sociedade dá trabalho. Mas queimar a boneca de Judith Butler não resolve seu problema de tesão com a pessoa trans (BUTLER 2017). Assim como ignorar um câncer, fingir que ele não existe, não tomar nenhuma medida e esperar que ele vá embora não é o melhor modo de combatê-lo.

Aproveitando esse ganchinho doloroso, meio grosso, sugerimos algumas perguntas para ajudar nesse problema. A primeira é, "isso é um problema?" Gostar de alguém é um problema? Gostar de si mesmo é um problema? Ser quem você é, é um problema? Nessa linha, aquela pessoa sendo quem ela é, te incomoda? Por quê? A segunda pergunta, também mais velha que andar para trás, é: "essa pessoa está me fazendo mal?" Como essa diferença entre nós me machuca? Por quê?

2 O TED de Chimamnda Ngozi Adichie sobre os perigos de uma única histórica, continua muito atual, mesmo dez anos passados. Disponível em: https://www.ted.com/talks/chimamanda adichie the danger of a single story?language=pt-br

\begin{tabular}{|l|c|c|c|c|c|c|}
\hline (c) Rev. Arqueologia Pública & Campinas, SP & v.13 & n.1 & p. & Jul/2019 & ISSN 2237-8294 \\
\hline
\end{tabular}


Tudo bem, sua religião não permite. Tudo bem, você acha estranho um homem com vagina. Tudo bem, é difícil de entender. Mas precisa matar? Precisa violentar? Precisa espancar? Precisa humilhar? Não, não precisa. Ser é muito mais que ter nascido. Viver é muito mais que pagar conta. A novidade não é sempre uma ameaça, assim como o nascimento de células novas não são sempre um câncer. A felicidade vem do respeito e da dignidade de vivermos nossas vidas, como nos apetece. E, para isso, precisamos deixar espaço para a liberdade $d x$ amiguinhx também.

\section{CARTA PELO CORPO}

Os viado, as trans, as sapa, ninguém existe só pra fazer sexo. A gente não é só sexo. Sexo é uma das várias relações sociais possíveis. E nós fazemos várias outras. $A$ gente se veste, corta cabelo, come, trabalha, urina, defeca (esses clássicos discursivos da equidade) e sangra. Muito.

Aliás, liberdade sobre o corpo não é só para engajar na luxúria. A sigla queer tem espaço, inclusive, para assexuados e sem gênero. Aquele pessoal que não tem vontade de usar seja lá o que tem entre as pernas. Aquela galera que não vê a carne tanto como um instrumento do sublime.

Falando sobre corpos inocentes, recai sobre nós mais um estigma injusto pedófilos. Por que? Gay gosta de comer criancinha? Igual comunista? Jogar o outro nesse balaio indefinido não ajuda a entende-lo. Pedofilia não é uma opção sexual, tanto quanto estuprar não o é. Pedofilia é uma violência. É usar o corpo de uma outra pessoa sem seu consentimento, sem seu entendimento ${ }^{3}$. É um estupro, é um assédio. E, acreditem, toda a legenda LGBT+ está com vocês na luta contra esse crime.

E, acreditem também, deixar de falar sobre esse crime não o resolve. A sexualidade, entendida como qualquer tipo de prazer corporal (sexo ou sem sexo) é um trabalho de conhecimento e respeito com seu próprio corpo. Falar de sexo e sexualidade nas escolas não é ler trechos do Kama Sutra. É ensinar autoconhecimento, respeito e dignidade a si e

3 Classificada como transtorno de ordem sexual pelo Catálogo Internacional de Doenças, ver: http://id.who.int/icd/entity/517058174. 
aos outros (DIAS 2018). Meu corpo, minhas regras. Seu corpo, suas regras. Ninguém invade o corpo de ninguém.

\section{CARTA ARQUEOLÓGICA}

Quando falamos que o gênero (e o sexo) são construções sociais, não dizemos que elas não são reais. Judith Butler, aquela mesma que queimaram como bruxa, também pensa assim (BUTLER 2017). Pessoas nascem com pipi, com vagina, com os dois. Pessoas nascem $X X, X Y, X X Y, X X Y Y, X Y Y$. Isso é real. $O$ útero e a gravidez, isso é real. Mas o que fazemos com isso, com esses corpos e esses cariótipos, é que varia. Nós definimos que a pessoa que engravida é chamada mulher. Que a pessoa que tem um pênis é chamada homem. Que mulher tem licença maternidade e homem tem menos (isso porque, agora, ele também tem licença). Que mulher que pega todos é puta (com aquele tom pejorativo à profissão) e homem é garanhão. Nós que definimos que $X Y$ é homem e $X X$ é mulher. Os outros são coisas estranhas, inomináveis. Repare, não estamos entrando no mérito dos desgastes fisiológicos que esses cariótipos implicam no indivíduo. Uma pessoa que sofre dores e males por sua genética, deve ser acompanhada e tratada para uma vida saudável e digna. Estamos entrando no demérito do senso comum que enquadra o mundo só na estatística do normal. Onde os desvios padrões (sim, padrões de desvio mesmo) são menos, quando são, simplesmente, menos comum. Repare de novo, não é um manifesto pela ditadura da minoria. Nem da maioria. Preferimos sem ditadura. E tu?

E o que a arqueologia tem a ver com isso? Tudo. Arqueologia descobre coisas antigas e belas, sim. Mas também descobre coisas recentes e feias. Arqueologia descobre as técnicas que usamos para transformar nossa realidade. Ela é uma disciplina que trabalha com tudo de material que o ser humano produz, ao longo do tempo. Uma mistura de arte com tecnologia. A maior parte das quais, inclusive, foram jogadas no lixo, esquecidas, perdidas ou escondidas. Nós, arqueólogues, adoramos chafurdar o lixo da realidade (GONZÁLEZ-RUIBAL 2008).

O que vemos na arqueologia, assim como veem na história, sociologia, antropologia, é que as pessoas, ao longo do tempo e espaço, tratam os corpos de maneiras diferentes. Constroem e validam corpos de maneira diferente. Sim, constroem. Do mais básico, o que 
comemos, ao mais complexo, às próteses que colocamos. E medimos o que é bom e o que é ruim. Dieta vegetariana, vegana, emagrecimento, proteica, da escassez e da fome. Perna mecânica, silicone nos vãos livres, anabolizantes. Exercícios direcionados, personal trainnig, esportes, roupas da moda, modelo plus size, modelo Gisele. Tatuagem, cicatriz de guerra, marcas de tortura, pintura, cobertura das vergonhas, vergonhas expostas, sem vergonhas.

$\mathrm{Na}$ cidade de Catterick/UK, antiga Cataractonium durante a ocupação romana no século IV d.C., arqueólogos encontraram dois esqueletos humanos, cujas anatomias sugeriam um indivíduo XY (homem), com adornos (colares, brincos, braceletes) associados ao universo romano feminino. Uma mulher trans? Quem sabe (PINTO 2011). Sabemos que aquele mundo era outro, então projetar uma categoria recente pode ser um problema. Assim como é um problema acreditar que, para essa mesma distância temporal, o padrão corporal era o do cis.

E quais os reais impactos disso na sociedade de então? Quer dizer que os romanos eram liberais? Sabemos, também, que os romanos eram, para nossos padrões (apenar de tudo, somos esperançosxs), extremamente machistas. Mulheres eram propriedade das famílias e não tinham nome próprio (só os de família).

Mas então, eles eram liberais ou não? Todo mundo se pegava (Fellini e Calígula na parada) ou não? Elxs eram elxs e nozes somos nozes. Estudar os outros, as outras, significa mergulhar no desconhecido. Assim com qualquer ciência. Isso significa, como dissemos no começo, que diferentes sociedades lidavam e construíam seus corpos de maneiras distintas. Isso significa que as relações sociais e as regras sobre cada um de nós, sobre nossos pipis, vaginas, peitos, bundas, pernas, cabeças, joelhos e pés, são, também, nossa responsabilidade. Há um limite para o que cai do céu, e o que fazemos com isso. Se a maçã caiu pela gravidade, nós podemos comê-la crua ou numa torta (com canela, sempre vai bem). Isso é legal, porque nos permite pensar um mundo novo, nos permite investir em nossa criatividade e liberdade. Isso é chato, porque dá um trabalho do caramba, ter que tomar cuidado até com as piadinhas nos almoços de família (sim, é chato, nós também achamos). Mexer em nossas certezas é mexer nas nossas bases. E ficar sem chão, um exercício de barra sem hora pra acabar. Mas gente, tem hora pra acabar sim. A gente pode descer, relaxar os braços e se preparar pra próxima rodada. Sair com aqueles amigos e amigas com quem você tem tudo em comum, leia um livro sussa, assiste um jogo sem 
problematização. Depois volta pra vida. Ninguém precisa morrer de cãibra. Mas a gente sabe que sedentarismo faz muito mal à saúde.

Queridos e queridas, tudo isso dá trabalho. A gente sabe. Não pensem que foi fácil pra gente não. Se olhar no espelho e ver que tem algo errado, sem saber o que é. Perceber que o tesão vem por pessoas quando, em tese, não deveria. Se dar conta que todo mundo fala de pegar geral, beijar 30 na festa e você se arrepia só de pensar em alguém se esfregando em ti. Que você pode estar entrando numa situação cada vez mais arriscada, só porque queres ser feliz, sem roubar, matar ou pedir nada. Sentir-se fora de si, querer sair, enquanto todo mundo quer te empurrar de volta pra dentro.

Mas enfim, c'est la vie. Uma amiga matemática uma vez disse que ela podia fazer cálculos para um número $n$ de dimensões ${ }^{4}$. Ou seja, um número qualquer de dimensões. Além do comprimento, altura e largura. Além do tempo. Isso, claro, foi o que ficou depois da terceira vez que ela explicou sobre matemática pura. Para nós, arqueólogues, números podem ser difíceis. Seria mais tranquilo, pra nós, se tudo se resumisse a uma soma simples. $1+1=2$. Mas talvez não fosse para essa amiga. Além de que a gente sabe que a vida tá cheia de equação de terceiro grau. Bora aprender?

\section{REFERÊNCIAS BIBLIOGRÁFICAS}

BUTLER, Judith. Judith Butler escreve sobre sua teoria de gênero e o ataque sofrido no Brasil. Folha de São Paulo. Tradução de Clara Allain. 21 nov. 2017. Disponível em: http://folha.com/no1936103. Acessado em 24 fev. 2019.

DIAS, Tatiana. Damares alves precisa perder o medo de meninos brincando de boneca. E a esquerda precisa conversar com ela. The Intercept Brasil. 8 dez. 2018. Disponível em: https://theintercept.com/2018/12/07/damares-alves-esquerda/. Acessado em 24 fev. 2019.

GONZÁLEZ-RUIBAL, Alfredo. Time to destroy. Current Anthropology. Vol. 49, no 2. 2008

PINTO, Renato. Duas rainhas, um príncipe e um eunuco: gênero, sexualidade e as ideologias do masculino e do feminino nos estudos sobre a Bretanha Romana. Tese (Doutorado em História). Programa de Pós-Graduação em História. Instituto de Filosofia e Ciências Humanas. Universidade Estadual de Campinas. 2011.254p. Disponível

em:

4 Dedicação especial ao carinho, paciência e amizade de Cintia Peixoto com pessoas de humanas que não sabem rachar a conta.

\begin{tabular}{|l|l|l|l|l|l|l|}
\hline (C) Rev. Arqueologia Pública & Campinas, SP & v.13 & n.1 & p. & Jul/2019 & ISSN 2237-8294
\end{tabular}


http://repositorio.unicamp.br/bitstream/REPOSIP/280841/1/Pinto Renato D.pdf. Acessado em 24 fev. 2019.

REDTUBE. Redtube \& Brazil - Pornhub insights. Pornhub insights. 05 fev. 2016. Disponível em: https://www.pornhub.com/insights/redtube-brazil. Acessado em 24 fev. 2019.

SOUTO, Luiza. Assassinatos de LGBT crescem 30\% entre 2016 e 2017, segundo relatório. $\quad \mathrm{G}$ Globo. 17 jan. 2018. Disponível em: https://oglobo.globo.com/sociedade/assassinatos-de-lgbt-crescem-30-entre-2016-2017segundorelatorio-22295785. Acessado em 24 fev. 2019

Transgender Europe (TGEU). TMM Update Trans Day of Remembrance 2017. Transrespect. Disponível em: https://transrespect.org/en/tmmupdate-trans-dayremembrance-2017/. Acessado em 24 fev. 2019.

\section{SIGNATARIXS}

André Strauss (MAE/USP)

Bruna Cigaran Rocha (UFOPA)

Camila Pereira Jácome (UFOPA)

Débora Leonel Soares (MAE/USP)

Eduardo Kazuo Tamanaha (Instituto Mamirauá)

Erêndira Oliveira (MAE/USP)

Fábio Guaraldo Almeida (MAE/USP)

lgor M. M. Rodrigues (MAE/USP)

Juliana Salles Machado (Darq/UFS)

Lana G. Guimarães Melo (UFOPA)

Laura Furquim (MAE/USP)

Mariana Di Giustu (MAE/USP)

Márjorie Lima (Instituto Mamirauá)

Maurício André Silva (MAE/USP)

Milena Acha (Lintt/IB/USP)

Rafael Almeida (MAE/USP)

Thiago Kater (MAE/USP)

Ximena Villagran (MAE/USP) 